\title{
Effect of Fe-Ti oxides on Mo isotopic variations in lateritic weathering profiles of basalt
}

\author{
ZHIBING WANG ${ }^{1, *}$, JiNLONG MA ${ }^{1, *}$, JiE Li $^{1}$, Ti ZenG ${ }^{2}$, \\ ZHUOYING ZHANG ${ }^{1}$, XINYUE HE ${ }^{1}$, LE ZHANG ${ }^{1}$, \\ GANGJIAN WEI ${ }^{1}$ \\ ${ }^{1}$ State Key Laboratory of Isotope Geochemistry, Guangzhou \\ Institute of Geochemistry, Chinese Academy of Sciences, \\ Guangzhou 510640, China \\ ${ }^{2}$ CAS Key Laboratory of Marginal Sea Geology, Guangzhou \\ Institute of Geochemistry, Chinese Academy of Sciences, \\ Guangzhou, 510640, China
}

E-mail address: wangzhibing@gig.ac.cn

This study aimed to improve our understanding of processes controlling Mo isotopic compositions during extreme weathering of basalt and identify a long-term surface reservoir for light $\delta^{98} \mathrm{Mo}$ signatures, which are key to constraining riverine inputs of Mo isotopes to the oceans. A lateritic weathering profile of basalt from Hainan Island, South China, was studied by determining bulk Mo contents and $\delta^{98} \mathrm{Mo}$ values as well as $\delta^{98} \mathrm{Mo}$ values of extracted $\mathrm{Fe}-\mathrm{Mn}$ (hydro) oxides and residual phases, $\mathrm{Fe}-\mathrm{Ti}$ oxides in residual phases, and parent-rock minerals. The $\delta^{98} \mathrm{Mo}$ values at the top of the section and the bottom of the section are typically lighter than that for the parent rock, but values at middle section are heavier than for the parent rock. Atmospheric input and adsorption and desorption processes, accompanied by changing redox conditions, are likely to be the dominant factors controlling variations in $\delta^{98} \mathrm{Mo}$ values in the lateritic weathering profile. Chemical extraction experiments indicate that Fe-Mn (hydro) oxides are an important host of Mo in laterite samples, and these oxides control variations in the mobilization and redistribution of bulk Mo through adsorption and desorption, and account for heavy bulk $\delta^{98} \mathrm{Mo}$ values in the lateritic profile. Fe-Ti oxides (ilmenite and magnetite) in the residual phase are another important host of Mo in lateritic weathering products, accounting for light bulk $\delta^{98}$ Mo values. Owing to their high resistance to weathering and chemical erosion, Ti-Fe oxides might be a potential longterm surface reservoir for light $\delta^{98}$ Mo signatures. The results elucidate mechanisms of Mo isotopic fractionation during chemical weathering and improve understanding of the riverine input of Mo isotopes to oceans. 